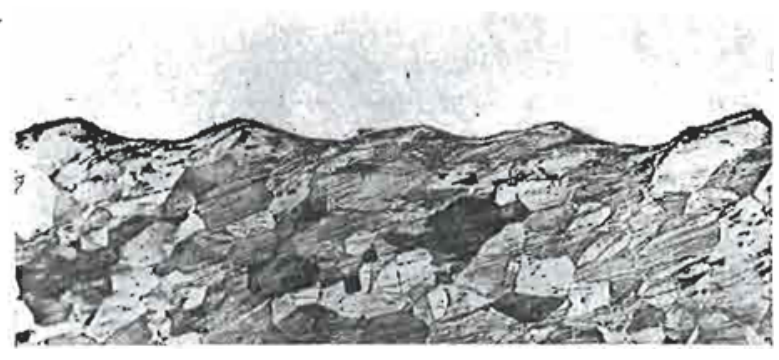

Fig. 5 Photomicrograph of gold clad nickel.

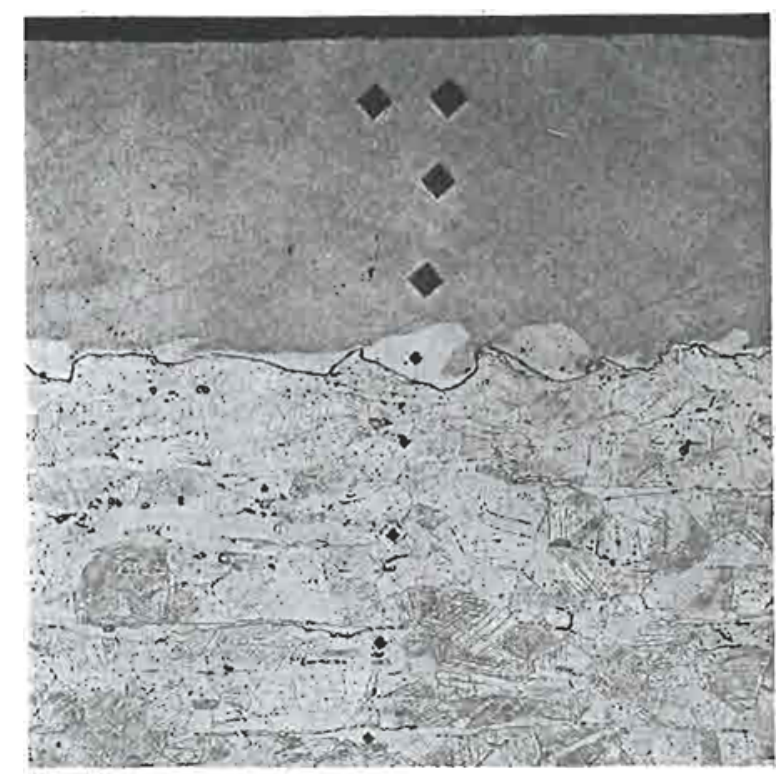

successfully to clad large tubular autoclaves with pore-free and firmly adherent gold linings. These are $400 \mathrm{~mm}$ in length with a wall thickness of 20 $\mathrm{mm}$ and are to be used in pressurised water reactors.

Figure 2 on page 35 shows an end view of the upper section of one such vessel. The use of a gold tube has been shown to be unnecessary, as simple gold sheet, more readily available commercially, can be satisfactory welded at the overlaps.

\section{References}

1 G. R. Cowan and A. H. Holtzmann, F. Appl. Phys,, 1963, 34, 928

2 R. Prümmer, Z. Werkstofftechnik/F. Materials Technology, 1972, 3, (6), 305-310

3 F. Jähn, R. Prummer and Ch. Liesner, Metall., 1974, 28, (1), 957-960

4 A. A. Deribas et al, Investigations of Changes in the Zones of Collision by Explosive Joining of Metals, Symposium on Dynamic Pressure, Paris 1967, 351-354

The technique described here has been used

\title{
New Thick Film Gold Conductors
}

The extensive range of gold-based thick film conductor preparations now available to the user was recently reviewed by $\mathrm{Dr} \mathrm{R} . \mathrm{H}$. Caley in this journal (Gold Bulletin, 1976, 9, (3), 70-75). Steady improvements and modifications to these products have assisted significantly in enhancing the performance and reliability of microelectronic circuitry.

Two further products have now been announced by the Electronic Materials Division of $\mathrm{Du}$ Pont. One, identified as gold conductor 9910 , is specifically designed for applications where aluminium wire bonding is to be used in high reliability hybrid microcircuits and in multilayer structures for interconnecting arrays of monolithic integrated circuits. Test data, using ultrasonic bonding, have shown that this composition provides superior aluminium wire bonding with high pull strengths after ageing at $150^{\circ} \mathrm{C}$ for long periods, The resistivity obtained is from 3 to 5 milliohms per square, and it is reported to have good adhesion to 96 to 99.5 per cent alumina and beryllia substrates together with good solderability with the usual germanium-gold, tin-gold and tin-leadindium solders.

The second new product, 9791 , is a mixed bonded material providing good adhesion both to the substrate and to a new dielectric composition. It provide resistivities of 2 to 5 milliohms per square, with resolution of 5 mil lines and vias for high density interconnections. It is recommended for eutectic die, gold wire and beam-lead bonding applications. 